\title{
Mussel-mimetic self-healing polyaspartamide derivative gel via boron-catechol interactions
}

\author{
B. Wang, Y. S. Jeon, H. S. Park, Y. J. Kim, J-H. Kim* \\ School of Chemical Engineering, Sungkyunkwan University, Suwon 440-746, Korea
}

Received 4 February 2015; accepted in revised form 20 April 2015

\begin{abstract}
The catechol group from catechol of 3,4-dihydroxyphenethylamine (DOP, dopamine) has the ability to interact with metal ions to form non-covalent bonds in polymer chains. In this study, a novel kind of mussel-inspired copolymer, dopamine-conjugated poly(hydroxyethyl aspartamide), polyAspAm(DOP/EA), was synthesized and its interaction with boric acid $\left(\mathrm{H}_{3} \mathrm{BO}_{3}\right)$ to form a cross-linked gel via boron-catechol coordinative binding was investigated. The copolymer was designed to contain a $\mathrm{pH}$ responsive adhesive catechol group, which reversibly underwent gelation through the metalcatechol binding, as proved by UV-Vis spectroscopy. When the $\mathrm{pH}$ is increased from acidic conditions to a specified $\mathrm{pH}$ $(\mathrm{pH}>9)$, the $\mathrm{B}(\mathrm{OH})_{3}$ is considered to have a functionality of two to bind catechols, leading to bis-complexes. In addition, the reversibility of the boron-catechol bonds provides self-healing characteristics to the polyAspAm gels. The rheological results showed that boron-catechol coordination could lead to quick and full recovery after the fracture of a gel specimen. This novel pH-responsive and self-healing gel system has potential in various applications including smart hydrogels, medical adhesives, and sealants.
\end{abstract}

Keywords: polymer gels, self-healing, polyaspartamide, boron-catechol interactions

\section{Introduction}

Bio-inspired polymers and soft gel-like materials have been extensively reviewed as novel materials for various applications due to their specific functionality and desirable mechanical properties with dynamic bonding interactions $[1,2]$. Marine mussels withstand high-energy wave impacts in rocky seashore habitats by fastening tightly to surfaces with tough and self-healing proteinaceous fibers called byssal threads, which are heavily decorated with DOPA, a catecholic functionality [3, 4]. Covalent bonding or non-covalent interactions (such as hydrogen bonding [5, 6], $\pi-\pi$ interactions [7], metal-ligand coordination bonding [8-10], or guest-host interactions [11] can form soft three-dimensional polymeric network hydrogels, which are defined as chemical gels or physical gels, respectively. In covalent hydrogels, it is difficult to induce a sol-gel transition in response to external stimuli or provide a selfhealing mechanism. In contrast, non-covalent hydrogels can easily respond to the external environment, however, they have poor mechanical properties. Unlike covalent bonds, which are generally irreversible, metal coordination bonds in byssal threads have the capability of reforming after rupture $[9,12]$. Thus, mussel-inspired, self-healing materials can be designed, which possess the ability to heal mechanical failure after rupture. Currently there are lots of reports considering self-healing hydrogel based on dynamic crosslinkage. Zhang et al. [13] presented an inexpensive, simple, and rapid method to prepare dynamic hydrogels using chitosan and telechelic PEG as main components which can control the release of drugs and other bioactive macromole-

\footnotetext{
${ }^{*}$ Corresponding author, e-mail: kimjh@skku.edu

(c) BME-PT
} 
cules. An inexpensive and biocompatible self-healing hydrogel for injectable cell therapy carrier was also investigated by Yang et al. [14]. Recently, some significant work has focused on non-covalent hydrogels, which are cross-linked by reversible interactions based on metal-ligand coordination in the polymer chains; these can provide stimuli responsiveness, magnetic self-healing and good mechanical properties [8-10, 15-20]. Because of the thermodynamics and kinetic properties of metal-ligand coordination bonds, metal-ligand interactions can provide stable, reversible crosslinking points between polymers [21]. Recently, some researchers reported mussel-inspired stimuli responsive and self-healing hydrogels containing dynamic metal $\left(\mathrm{Fe}^{3+}\right)$-catechol interactions. The hydrogels are $\mathrm{pH}$-sensitive, i.e., the $\mathrm{Fe}^{3+}$ mono-catecholate, bis-catecholate, or tris-catecholate complexes are formed when the $\mathrm{pH}$ is increased to a specified $\mathrm{pH}[21,22-25]$. Krogsgaard et al. [9] reported a self-healing multi-responsive system by incorporating additional features of the mussel adhesive proteins for drug delivery platforms. They found that the catechol- $\mathrm{Fe}^{3+}$ complexes worked as cross-links and a sufficient number of cross-links formed a hydrogel. Competition between oxidation and coordination in catechol groups were investigated by $\mathrm{Xu}$ et al. [4]. They designed a simple polystyrene copolymer containing catechol groups to show that catechol units could afford a dual crosslinking system based on oxidative coupling with oxygen or coordinative coupling through $\mathrm{Fe}^{3+}$ [4].

Boric acid is a typical Lewis acid, which has several unique characteristics for biomedical applications [26]. In aqueous media, the Lewis acidity of boron facilitates the reaction with water to abstract $\mathrm{OH}^{-}$, and the trigonal boron is converted to an anionic tetrahedral geometry [26]. Because the pKa value of boric acid is 4.5-10, anionic tetrahedral boron formed by reaction of the neutral boric acid with a diol of catechol is generally considered hydrolytically unstable [27-29]. In aqueous systems, boric acids maintain equilibrium between an undissociated neutral trigonal form and a dissociated anionic tetrahedral form [28]. Upon increasing the $\mathrm{pH}$ to the normal $\mathrm{pKa}$ value range of boric acid, $\mathrm{B}(\mathrm{OH})_{3}$ is considered to have a functionality of two to bind catechols, leading to bis-complexes. Vatankhah-Varnoosfaderani synthesized and characterized a musselinspired copolymer, poly(dopamine methacrylate-co $-N$-isopropylacrylamide) [p(DMA-co-NIPAM)], and its interaction with boric acid $\left(\mathrm{H}_{3} \mathrm{BO}_{3}\right)$ [30]. The supramolecular polymer gel was sensitive to three different external stimuli and a rapid self-healing property based on boron-catechol interactions was demonstrated. Other research groups also developed artificial stimuli-responsive gels, including $\mathrm{pH}-$ responsive [29-33] and sugar-responsive [34] polymer gels via boric-catechol complexation for biomaterials applications.

In this study, we present a $\mathrm{pH}$-responsive self-healing hydrogel, inspired by adhesive mussel proteins, based on 3,4-dihydroxyphenethylamine(or dopamine)conjugated polyaspartamide. Polyaspartamides are water-soluble, non-toxic, non-antigenic and biodegradable polymers, and can be obtained from the aminolysis of polysuccinimide (PSI), which is easily prepared by thermal polycondensation of D,L-aspartic acid, the thermal polycondensation product of aspartic acid monomer [35-39]. By using boric acid $\left(\mathrm{H}_{3} \mathrm{BO}_{3}\right)$, the mussel-inspired copolymer exhibited a reversible gelation by $\mathrm{pH}$ change, which was based on boron-catechol coordination binding. In addition, the dynamic complexation between boron-catechol coordination can lead to the formation of a rapid self-healing smart material. Hence, this novel biocompatible gel system has potential in several applications including smart hydrogels, medical adhesives, and sealants.

\section{Experimental}

\subsection{Materials and instruments}

L-aspartic acid (98+\%), ortho-phosphoric acid (98\%), $\mathrm{N}, \mathrm{N}$-dimethylformamide (99.8\% anhydrous, DMF), dopamine hydrochloride (DOP), ethanolamine (99\%, EA), triethylamine $(99.5+\%)$, sodium hydrosulfite ( $\sim 85 \%)$, acetic acid $(99+\%)$, and boric acid $(99.5 \%+)$ were purchased from Aldrich Chemical Co. Acetone was obtained from DaeJung Chemical Co. (Siheung, Korea). All other chemicals purchased were of sufficient quality and used as received.

The ${ }^{1} \mathrm{H}$ NMR spectra were recorded on a Unity Inova-500 (Varian, Palo Alto, CA, USA) spectrometer using DMSO and $\mathrm{D}_{2} \mathrm{O}$ as the solvents. The structures of the PolyAspAm samples were analyzed by Fourier transform infrared (FT-IR) spectroscopy (Bruker IFS 66/S, Bruker, Germany). UV-Vis absorption data were recorded on a Molecular Devices SpectraMax M5 spectrometer (California, USA) using a quartz cuvette with a path length of $1 \mathrm{~cm}$ at room temperature. Solutions of $20 \mathrm{mg} / \mathrm{mL}$ PolyAs- 
pAm(DOP50/EA50) with a sufficient amount of $\mathrm{B}(\mathrm{OH})_{3}$ solution $\left(\right.$ catechol $/ \mathrm{B}(\mathrm{OH})_{3}$ mole ratio $=$ 2.0) were prepared. The $\mathrm{pH}$ of the solutions was then increased by the addition of a $\mathrm{NaOH}$ solution under a nitrogen blanket followed by stirring for $12 \mathrm{~h}$ and dilution of the solutions with different $\mathrm{pH}$ buffers.

\subsection{Synthesis of polysuccinimide (PSI)}

L-aspartic acid (30 g) and 98\% ortho-phosphoric acid (30 g) (50:50 wt. ratio) were put into a round bottom flask and mixed at room temperature. The mixture was heated slowly from room temperature to $180^{\circ} \mathrm{C}$ under reduced pressure in about $30 \mathrm{~min}$, and maintained at $180^{\circ} \mathrm{C}$ for $4.5 \mathrm{~h}$. Then, the reaction mixture was cooled, and DMF was added to dissolve the product. The resulting solution was precipitated in excess water, and the precipitate was washed several times with water to remove the residual phosphoric acid until the solution reached $\mathrm{pH}=7$. The product was finally dried at $70^{\circ} \mathrm{C}$ in vacuum for 3 days to obtain PSI in a white powder form. The molecular weight was estimated to be approximately $130000 \mathrm{Da}$, as calculated from an empirical equation relating the solution viscosity to the molecular weight [40].

\subsection{Synthesis of polyaspartamide derivatives, polyAspAm(DOP/EA)}

To synthesize polyAspAm(DOP/EA), $1 \mathrm{~g}$ of PSI was dissolved in $30 \mathrm{~mL}$ of DMF in a three-neck roundbottom flask, and $0.790 \mathrm{~g}$ of DOP $(50 \mathrm{~mol} \%$ based on succinimide unit) and $1.723 \mathrm{~mL}$ of triethylamine were subsequently added. The flask was placed in an oil bath maintained at $80^{\circ} \mathrm{C}$, and the reaction was carried out under a nitrogen atmosphere for $24 \mathrm{~h}$ in the presence of $0.05 \mathrm{~g}$ sodium hydrosulfite to prevent oxidation of dopamine groups. A $50 \mathrm{~mol} \%$ excess $(0.528 \mathrm{~mL})$ of EA was then added slowly to the reaction mixture, and the mixture was stirred at room temperature for another $24 \mathrm{~h}$. The resulting mixture was precipitated in $500 \mathrm{~mL}$ of cold acetone. The filtered product, polyAspAm(DOP/EA), was dissolved in water, and glacial acetic acid was added until the solution $\mathrm{pH}$ reached $\mathrm{pH} 4$. The final polymer solution was dialyzed for 3 days and lyophilized.

\subsection{Gelation of polyAspAm(DOP/EA) with boric acid}

The polyAspAm(DOP/EA) polymers with different catechol group concentrations were used for the preparation of aqueous solutions and reversible gels. As an example, $0.1 \mathrm{~g}$ polyAspAm (DOP50/ EA50) was dissolved in $0.5 \mathrm{~mL}$ deionized water, into which a sufficient amount of $\mathrm{B}(\mathrm{OH})_{3}$ solution (catechol $/ \mathrm{B}(\mathrm{OH})_{3}$ mole ratio $\left.=2.0\right)$ was added. The $\mathrm{pH}$ of the mixtures was increased to the desired final $\mathrm{pH}$ of 9 by the addition of a $0.1 \mathrm{~N} \mathrm{NaOH}$ solution under a nitrogen blanket. The mixture was mechanically mixed to produce gel via boron-catechol coordination binding.

\subsection{Rheological properties}

The rheological measurements of the polyAspAm gel were conducted on a Bohlin rotational rheometer (Malvern Instruments, U.K.) with parallel plate geometry of $20 \mathrm{~mm}$ diameter. Oscillatory shear testing of gels as a function of frequency was performed at constant strain of $1 \%$ to measure elastic modulus $\left(G^{\prime}\right)$, viscous modulus $\left(G^{\prime \prime}\right)$ and complex viscosity at $25^{\circ} \mathrm{C}$. Self-healing tests were performed by straining each gel to failure under increasing strain from $0.1 \%$ to $1000 \%$, then using time sweep test to monitor the recovery $G^{\prime}, G^{\prime \prime}$ as a function of time.

\section{Results and discussion}

\subsection{Synthesis and characterization of polyAspAm(DOP/EA)}

As shown in Figure 1, novel dopamine-modified polyAspAm derivatives were synthesized from PSI through a successive aminolysis reaction with quantitative dopamine and excess EA. The structure and composition of the PSI and polyAspAm(DOP/EA) were confirmed using ${ }^{1} \mathrm{H}$ NMR spectroscopy (Figure 2). The methine proton (at $5.3 \mathrm{ppm}$ ) of the initial succinimide ring disappeared completely after a series of aminolysis reactions, suggesting a quantitative ring-opening to produce the polyAspAm derivatives. Peaks a, $\mathbf{b}$ and $\mathbf{c}$ were assigned to the aromatic protons of the dopamine phenyl group, and peaks $\mathbf{e}$ and $\mathbf{f}$ were assigned to the methylene protons of the EA pendant, respectively. The composition of each group in the polyAspAm(DOP/EA) copolymer was determined from the integration ratio between peaks a, $\mathbf{b}, \mathbf{c}(\delta=6.3-6.8)$, and $\mathbf{d}(\delta=2.7)$. Table 1 shows the composition of three different polyAspAm(DOP/EA) copolymers prepared.

Figure 3 shows the FT-IR transmittance spectra of PSI (spectrum a) and polyAspAm(DOP50/EA50) (spectrum b). Spectrum a of PSI showed two characteristic bands at 1727 and $1393 \mathrm{~cm}^{-1}$, which were 

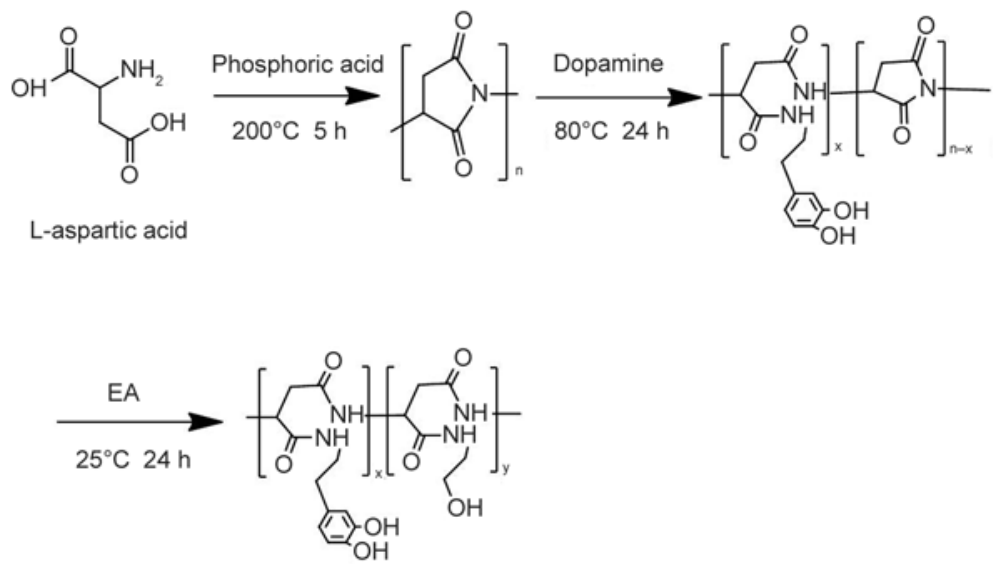

Figure 1. Reaction scheme for polyAspAm(DOP/EA) synthesis

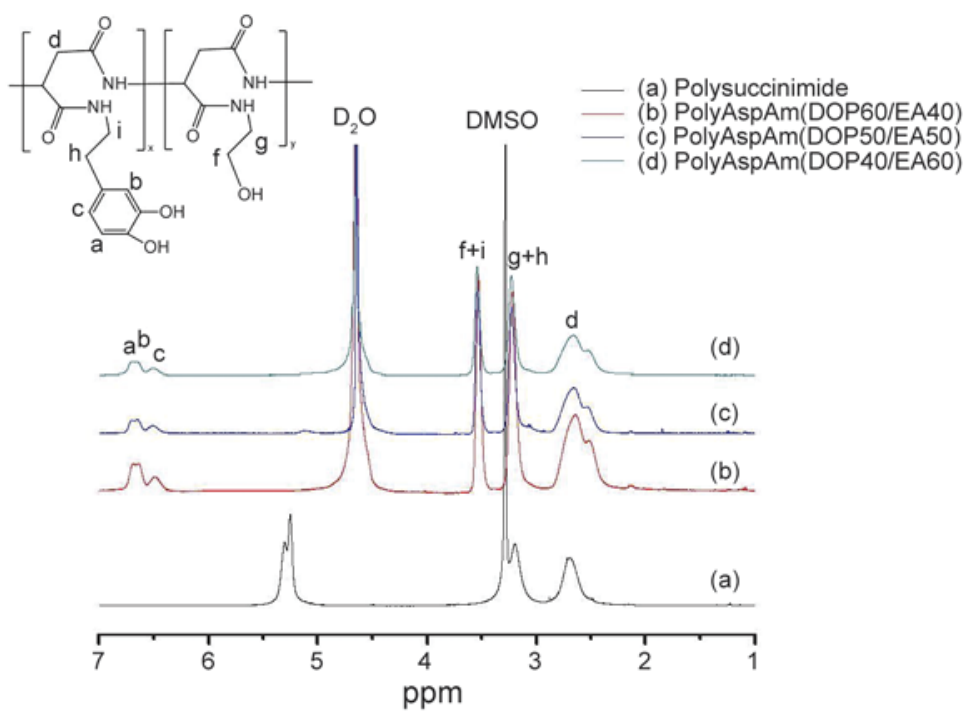

Figure 2. ${ }^{1} \mathrm{H}$ NMR spectra of dopamine-conjugated polyAspAm derivatives

Table 1. Composition of each pendant group in the polyAspAm(DOP/EA) copolymers

\begin{tabular}{|l|c|c|c|}
\hline \multicolumn{1}{|c|}{ Content [mol\%] } & PolyAspAm(DOP40/EA60) & PolyAspAm(DOP50/EA50) & PolyAspAm(DOP60/EA40) \\
\hline Dopamine & 22 & 25 & 27 \\
\hline Ethanolamine & 78 & 75 & 73 \\
\hline
\end{tabular}

The proportion of each pendant group in the polyAspAm(DOP/EA) copolymers was determined by ${ }^{1} \mathrm{H}$ NMR analysis

attributed to the absorption of the imide ring. In the spectrum of $b$, the peaks relating to succinimide disappeared and new peaks relating to amide I and amide II bands at 1635.4 and $1519.4 \mathrm{~cm}^{-1}$, respectively, are seen. The absorption bands of 1365.7 and $1281.5 \mathrm{~cm}^{-1}$ could be assigned to phenolic $\mathrm{C}-\mathrm{O}-\mathrm{H}$ of catechol groups in the dopamine. The broad band in the range of 3500-3200 $\mathrm{cm}^{-1}$ was assigned to $-\mathrm{OH}$ and $-\mathrm{NH}$ of the copolymer. As a result, both ${ }^{1} \mathrm{H}$ NMR and FT-IR analyses confirmed the successful synthesis of polyAspAm derivatives with dopamine pendants.

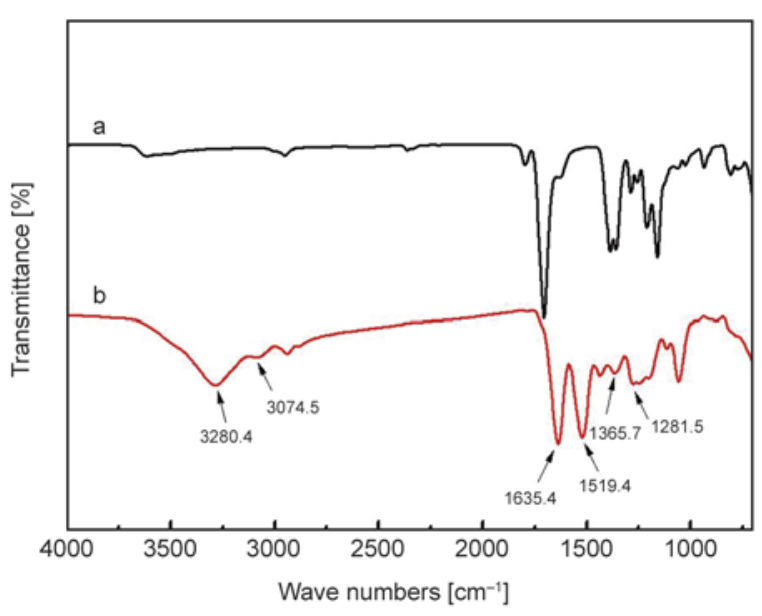

Figure 3. FT-IR Spectra of PSI (a) and polyAspAm(DOP/ EA) (b) 


\subsection{Preparation and characterization of polyaspartamide derivative gels based on boron-catechol interactions \\ 3.2.1. pH-responsive gelation}

Boric acid, $\mathrm{B}(\mathrm{OH})_{3}$, is a typical Lewis acid, which is dissolved in water to generate a weak electrolyte. Hydrated boric acid generates a small amount of ionizing $\mathrm{B}(\mathrm{OH})_{4}^{-}$and $\mathrm{H}^{+}$ions, and the resulting solution is weakly acidic. $\mathrm{B}(\mathrm{OH})_{3}$ is known to be capable of forming complexes with catechol and substituted catechols [41]. Figure 4 shows the general overall reactions with both an addition (one ligand donor atom was present in a non-occupied site on boron) and a substitution reaction (the second ligand donor atom displacing an $\mathrm{OH}^{-}$from boron). The boron atom has four coordinative bonds with diols from catechol groups, the ligand being bidentate.

Figure 5 shows the $\mathrm{pH}$ effect on the gelation of polyAspAm gel, where the polyAspAm(DOP50/EA50) copolymer was treated with boric acid $\left(\mathrm{B}(\mathrm{OH})_{3} /\right.$ DOP $=1: 2$ molar ratio, $25 \mathrm{mg} / \mathrm{mL}$ of the polyAspAm) at different $\mathrm{pH}$ values of 8,9 and 12 , respectively. At $\mathrm{pH}$ 8, the polyAspAm solution containing boron exists in a liquid state with a yellow color, suggesting that $\mathrm{B}(\mathrm{OH})_{3}$ formed catechol-boron monocomplexes (Figure 5a). When the $\mathrm{pH}$ was increased from acidic conditions to a specified $\mathrm{pH}$ of $\mathrm{pH}=9$, the $\mathrm{B}(\mathrm{OH})_{3}$ was considered to have a functionality of two to bind catechols to form non-covalent crosslinking via boron-catechol coordinative complexation.

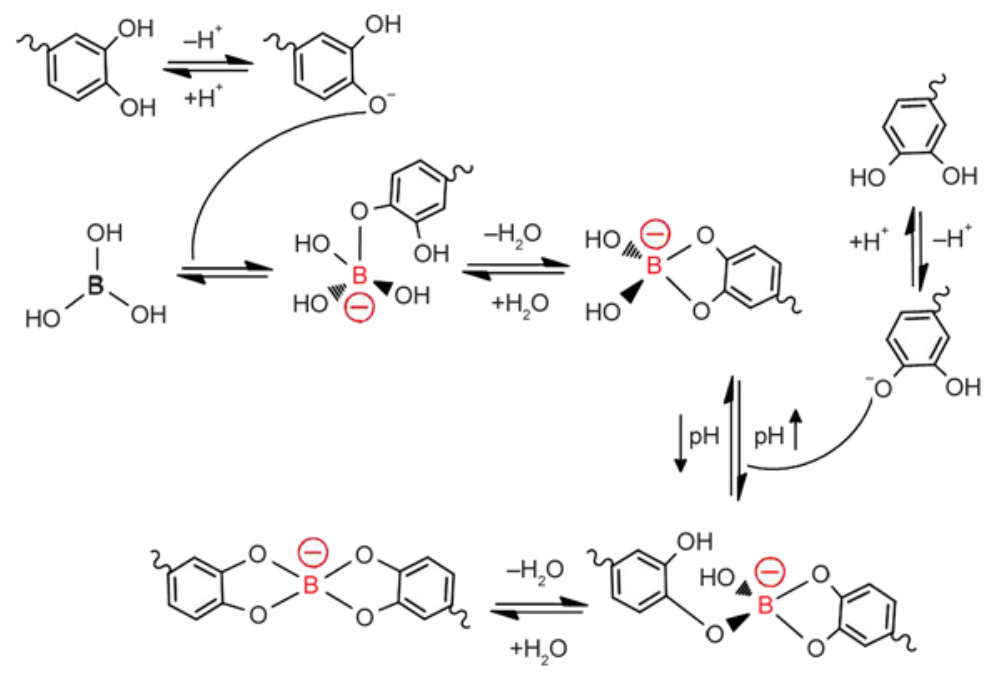

Figure 4. Equilibrium reaction between catechol groups of polyAspAm(DOP/EA) and boric acid

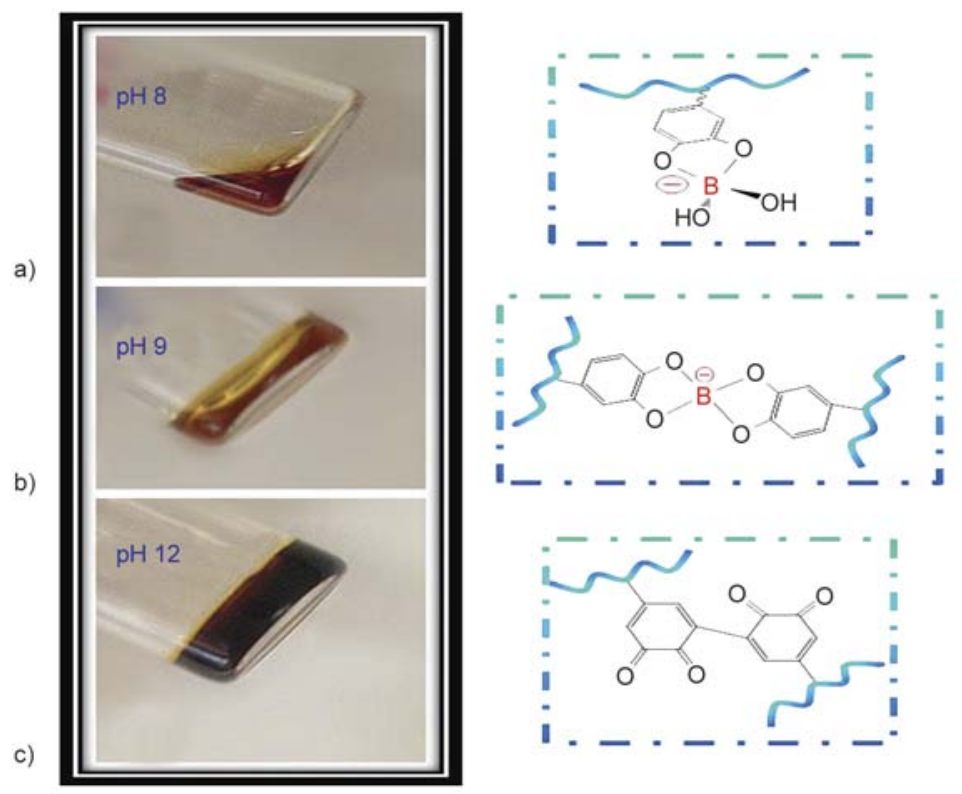

Figure 5. Photographs of polyAspAm(DOP/EA) with boric acid gel at different $\mathrm{pH}$ conditions. The physical state, color, and estimated chemical interactions of polyAspAm(DOP/EA) with $\mathrm{B}(\mathrm{OH})_{3}$ at $\mathrm{pH}$ values of (a) 8, (b) 9 and (c) 12 were demonstrated 
In addition, the color changed to the characteristic dark red (Figure 5b). At a higher $\mathrm{pH}$ of 12, it seemed catechol quinone-mediated covalent coupling had occurred to form a permanently cross-linked dark brown gel (Figure 5c) caused by the possible oxidation of catechol groups.

Further evidence of the presence of catechol- $\mathrm{B}(\mathrm{OH})_{3}$ complexes was gained from UV-vis spectroscopic measurements. Figure $6 \mathrm{a}$ showed the dominance of catechol- $\mathrm{B}(\mathrm{OH})_{3}$ complexes under different $\mathrm{pH}$ conditions. When the solution is acidic, boric acid does not interact with catechol groups, showing the same spectra as that of a pure polyAspAm copolymer solution with only one peak $\left(\lambda_{\max }=280 \mathrm{~nm}\right)$, assignable to the catechol group. However, boron-catechol bonds are formed when the $\mathrm{pH}$ of the solution is increased to $\mathrm{pH} \mathrm{9}$, as the corresponding absorption is shown at $490 \mathrm{~nm}$. The peak at $320-330 \mathrm{~nm}$, appearing in alkaline condition, is related to the oxidation of catechol groups that is not avoidable. When the solution $\mathrm{pH}$ was decreased from $\mathrm{pH} 9$ to $\mathrm{pH} 8$, the peak at $490 \mathrm{~nm}$ disappeared due to the reversible boron-catechol interactions. Figure 6b-1 showed the gel formed from catechol- $\mathrm{B}(\mathrm{OH})_{3}$ at $\mathrm{pH}$ 9. It was transited to a

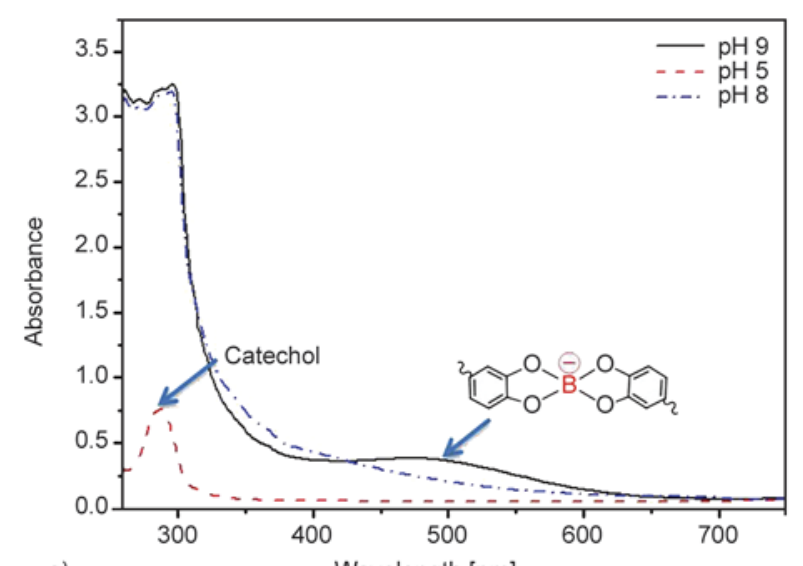

a)

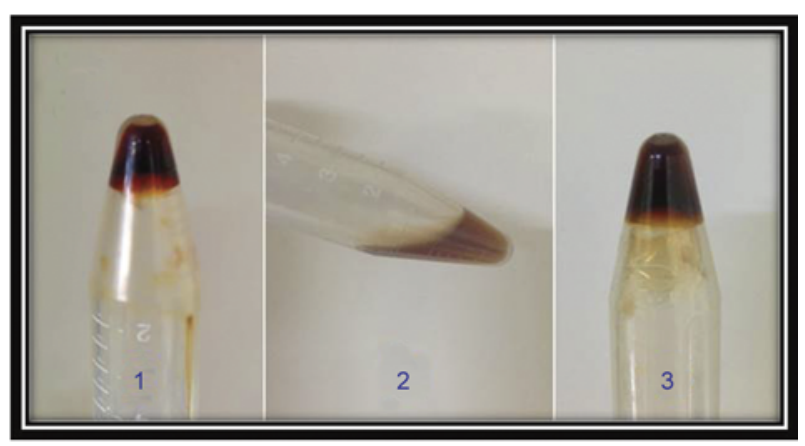

b)

Figure 6. (a) UV-Vis absorbance of polyAspAm(DOP/EA) with boric acid solution. (b) Photographs of reversible gel formation liquid after adjusting the $\mathrm{pH}$ to 5 (Figure 6b-2). When the $\mathrm{pH}$ is increased from 5 to a specified $\mathrm{pH}=$ 9, the gelation occurred again as shown in Figure 6b3 . This observation suggests that dynamic complexation between boric acid and catechol groups at $\mathrm{pH} 9$ can lead to reversible gelation.

\subsubsection{Reversibility of polyAspAm gel formation}

In many prior investigations on the reversible noncovalent catechol-boron bonds, oxidation of the catechol group was a critical issue. Gelation experiments have been carried out to explain two alternative gelation mechanisms in different $\mathrm{pH}$ conditions. Increasing $\mathrm{pH}$ can lead to catechol group oxidation of the quinone and subsequent formation of irreversible covalent crosslinking. In order to prove these two mechanisms, the same amount of $\mathrm{pH}=5$ buffer was added to each gel sample, which was prepared under different $\mathrm{pH}$ conditions. The reversible coordinatively cross-linked gel (Figure 7a) completely dissolved after $10 \mathrm{~min}$ (Figure 7d). The $\mathrm{B}(\mathrm{OH})_{3}$-catechol complex system is assumed to be in dynamic equilibrium, which means that a number of free catechols still exist in the system. Upon increasing the $\mathrm{pH}$, the free catechol would be oxidized to the quinone, which finally damages the reversibility of gel formation. Figures $7 \mathrm{~b}$ show the

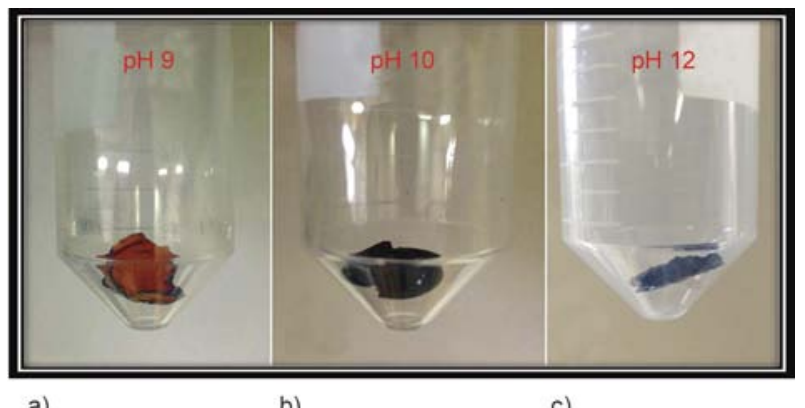

a)

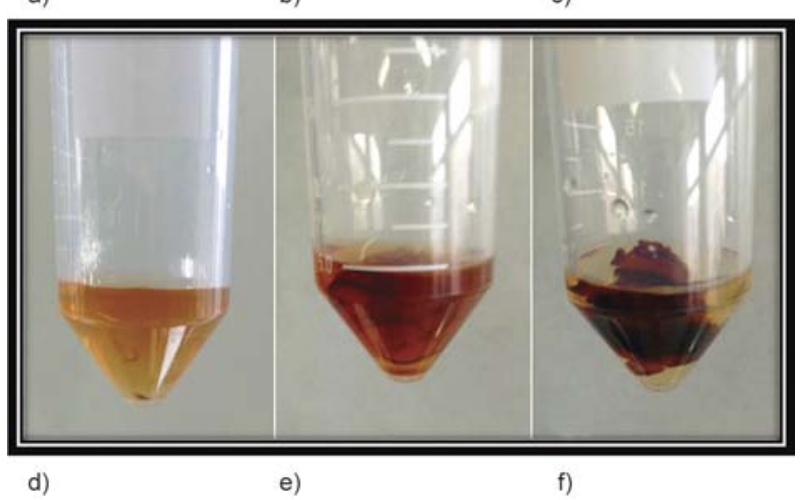

Figure 7. Photographs of gel samples: the original gels (a), (b) and (c) (gel formed at different $\mathrm{pH}$ conditions) were added a certain amount of $\mathrm{pH} 5$ buffer solution to form different states (d), (e) and (f). 
state of partially coordinative cross-linked gels, where some of the irreversible covalently crosslinked gels remained in a gel state (Figure 7e). In contrast, the dark brown gel (Figure 7c), formed at a higher $\mathrm{pH}$ of 12 , remained almost the same without dissolution (see Figure 7f) due to the covalent crosslinking by the oxidation process.

\subsection{Rheological properties of gels based on boron-catechol interactions}

To investigate the rheological behavior of DOPpolyAspAm gels, dynamic mechanical analysis was performed with three different samples (Figure 8). The elastic modulus $\left(G^{\prime}\right)$ and viscous modulus $\left(G^{\prime \prime}\right)$ were measured as a function of frequency at a constant strain of $1 \%$ at $25^{\circ} \mathrm{C}$. The elastic moduli of the three gel samples were highly dependent on frequency, and were more elastic at higher shear rates, showing a plateau. $G^{\prime \prime}$, however, increased along with decreasing frequency in the lower frequency range, suggesting a more viscous character at a decreased shear rate. The $G^{\prime}$ plateau increased slightly with increasing DOP content, probably due to an increase in the crosslinking density.

Figure 9 compared the modulus of two different gel samples obtained at $\mathrm{pH} 9$ and $\mathrm{pH} 12$. Both the boroncatechol coordination and covalent crosslinking via oxidative coupling can contribute to gel formation, but, the latter becomes more important at higher $\mathrm{pH}$ values. Although the type of cross-linking shifts from coordinative bonding to covalent bonding by increasing $\mathrm{pH}$ values from 9 to 12 , the elastic modulus $\left(G^{\prime}\right)$ of the $\mathrm{B}(\mathrm{OH})_{3}$-catechol cross-linked gel was over 20-fold higher than the covalently bonded gel. This result indicates that the boron-catechol coordi-

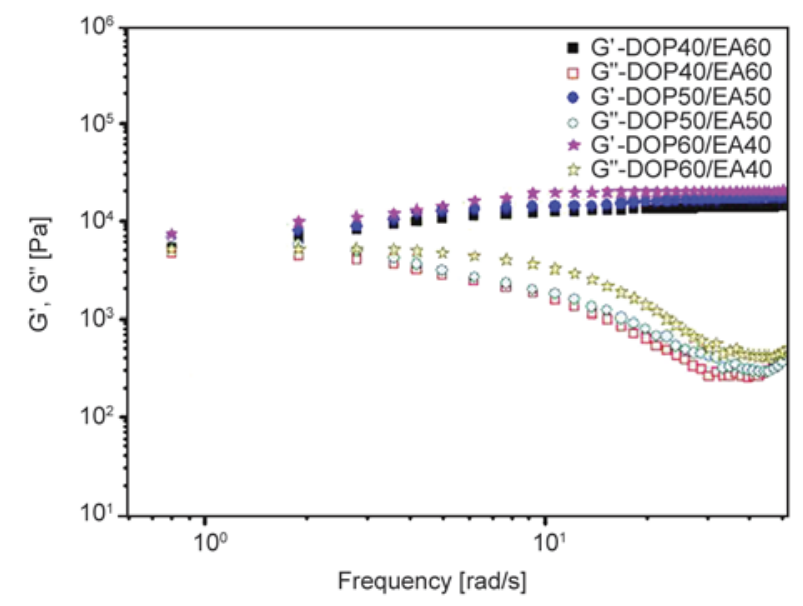

Figure 8. Rheological properties of gels made with dopamine-conjugated polyAspAm derivatives

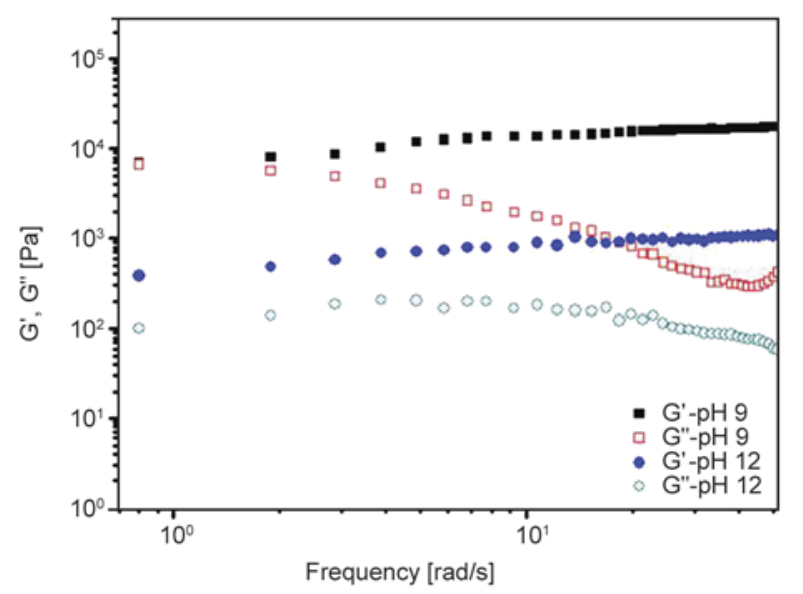

Figure 9. Comparison of moduli data in two different gels prepared at different $\mathrm{pH}$ values

native crosslinking density is significantly higher than that of quinone-mediated covalent cross-links, as boron-catechol mono-complexes, which remain in the covalently bonded gel, will prevent oxidative crosslinking, resulting in a lower mechanical stiffness of the gel.

The $G^{\prime}$ and $G^{\prime \prime}$ curves of polyAspAm gel at $\mathrm{pH} 9$ with different gelator concentrations $\left(\mathrm{B}(\mathrm{OH})_{3} /\right.$ catechol $=1: 2$ and 1:1 molar ratio) are presented in Figure 10 . When the molar ratio of $\mathrm{B}(\mathrm{OH})_{3} /$ catechol was changed from 1:2 to $1: 1$, both the elastic modulus $\left(G^{\prime}\right)$ and viscous modulus $\left(G^{\prime \prime}\right)$ decreased dramatically. Because a sufficient amount of boric acid should lead to a gel comprised of a bidentate crosslinked structure rather than an uncross-linked or mono-dentate one, the mole ratio between boron and catechol is important for generating maximum crosslinking. For this reason, it is suggested that the molar ratio of $\mathrm{B}(\mathrm{OH})_{3} /$ catechol $=1: 2$ can be consid-

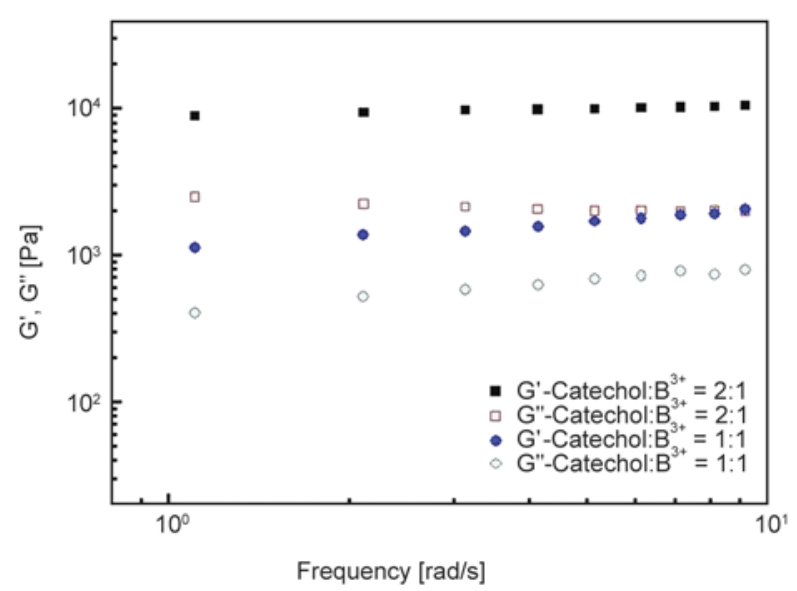

Figure 10. Comparison of moduli of polyAspAm gels made with different $\mathrm{H}_{3} \mathrm{BO}_{3}$ and DOP molar ratios 
ered as an ideal ratio to make gels based on boroncatechol interactions.

\subsection{Self-healing properties}

The dynamic complexation between boron-catechol coordination can lead to the formation of reversible self-healing gels. As depicted in Figure 10, a plate of DOP-polyAspAm gel (in pH 9) (Figure 11a), cut into two pieces, could be healed autonomously and rapidly in a whole piece by simply contacting the fractured surfaces together without any outer intervention (Figure $11 \mathrm{~b}$ and $11 \mathrm{c}$ ). In addition, no obvious cut line was seen in the region of attachment after about 10 min (Figure 11d). Figure 9e showed that the jointed parts after healing were strong enough to be stretched without fracturing by the tweezers. When the healed gel was cut into two pieces, the same selfhealing phenomenon was observed again wherever the gels were fractured, showing the property is repeatable and effective. This result can be ascribed to the dynamic complexation between boron and catechol groups.

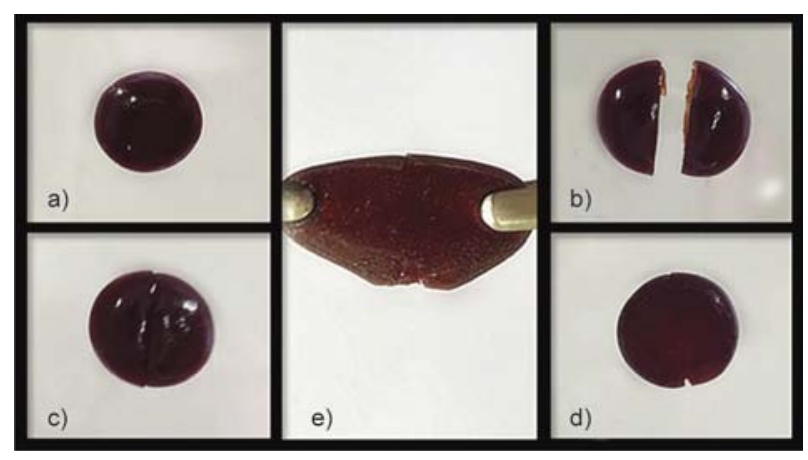

Figure 11. Photographs of evidence of self-healing: (a) the original sample, (b) sample cut into two pieces, (c) joining the pieces together, (d) the recovered sample and (e) the extended healed sample

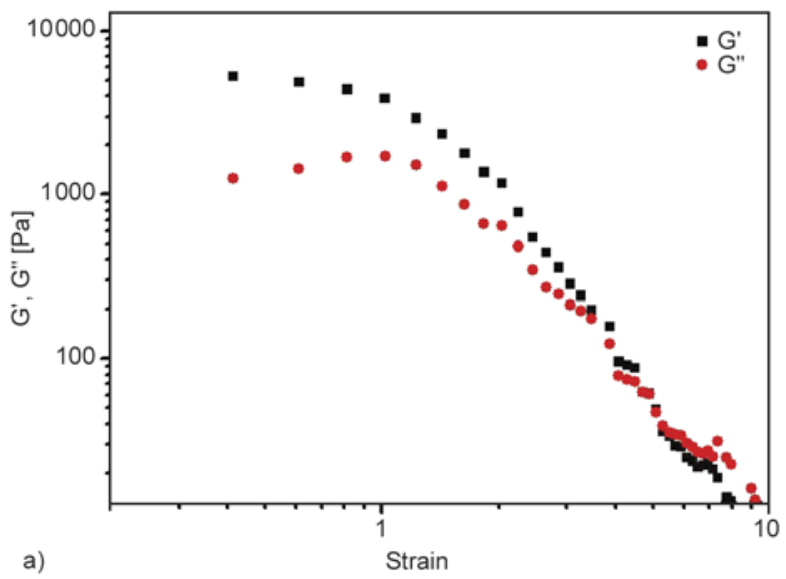

In order to further demonstrate the self-healing recovery capabilities of the DOP-polyAspAm gel after complete deformation, dynamic mechanical analysis was employed. Figure 12a shows a strain sweep analysis at constant frequency measured by oscillatory rheometry, where the deformation strain was increased from 0.1 to $1000 \%$. In the higher yield strain range, the elastic modulus $\left(G^{\prime}\right)$ and viscous modulus $\left(G^{\prime \prime}\right)$ decreased dramatically to result in gel failure. When the strain was increased to above $500 \%$, the $G^{\prime \prime}$ value exceeded $G^{\prime}$, suggesting the gel state changed from solid to liquid. In the time sweep (Figure 12b) test of the gel sample, after the failure and subsequent self-healing, the elastic modulus $\left(G^{\prime}\right)$ of the healed gel was found to recover to its original value, while the viscous modulus $\left(G^{\prime \prime}\right)$ decreased by about 2-fold compared to the original value. However, the value of $G^{\prime \prime}$ tended to increase continuously during the time sweep, suggesting a gradual structural rearrangement within the healed gel. To summarize, the above results suggest dopamine-modified polyaspartamide possesses a self-healing property via the reversible boron-catechol coordination binding, which can lead to quick recovery after failure. This novel gel system has potential in several applications, including smart hydrogels, medical adhesives, and sealants.

\section{Conclusions}

A novel $\mathrm{pH}$-responsive self-healing polyaspartamide derivative gel based on boron-catechol interactions has been prepared, and its rheological properties and self-healing behavior were investigated. The dynamic complexation between boric acid and catechol groups at $\mathrm{pH} 9$ can lead to reversible gelation, as evi-

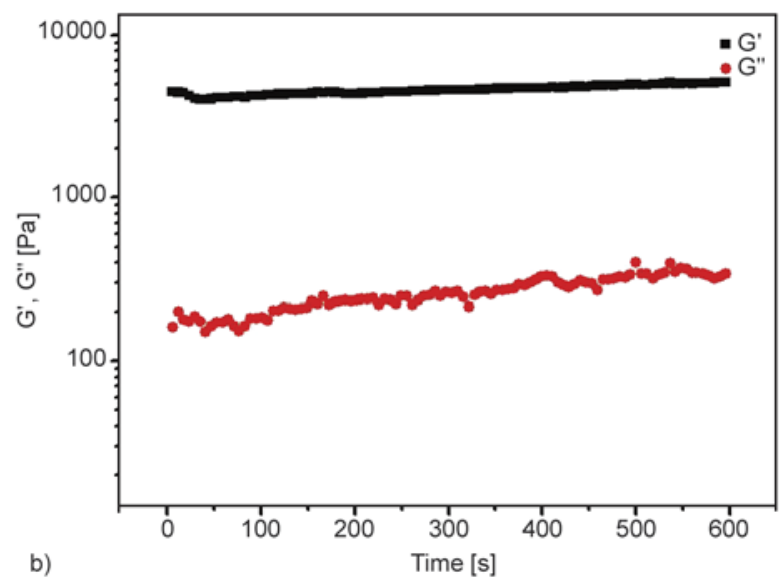

Figure 12. Self-healing behavior of polyAspAm(DOP/EA) with boric acid gel by strain sweep analysis followed by a time sweep analysis 
denced by the solubility behavior and UV-Vis spectroscopy. The polyAspAm gels are quickly self-healing, as evidenced by a full recovery after fracture of the gel specimen. In addition, the rheological results showed that $\mathrm{B}(\mathrm{OH})_{3}$-catechol coordinative cross-link density is higher than that of quinone-mediated covalent cross-links, and the molar ratio of $\mathrm{B}(\mathrm{OH})_{3} /$ catechol $=1: 2$ can be considered as an optimum ratio to make gels with improved mechanical properties.

\section{Acknowledgements}

This research was supported by the Basic Science Research Program through the National Research Foundation of Korea (NRF) funded by the Ministry of Education, Science and Technology (\#2011-0011464).

\section{References}

[1] Moulay S.: Dopa/catechol-tethered polymers: Bioadhesives and biomimetic adhesive materials. Polymer Reviews, 54, 436-513 (2014).

DOI: $10.1080 / 15583724.2014 .881373$

[2] Roberts M. C., Hanson M. C., Massey A. P., Karren E. A., Kiser P. F.: Dynamically restructuring hydrogel networks formed with reversible covalent crosslinks. Advanced Materials, 19, 2503-2507 (2007).

DOI: 10.1002/adma.200602649

[3] Lee B. P., Messersmith P. B., Israelachvili J. N., Waite J. H.: Mussel-inspired adhesives and coatings. Annual Review of Materials Research, 41, 99-132 (2011). DOI: 10.1146/annurev-matsci-062910-100429

[4] Xu H., Nishida J., Ma W., Wu H., Kobayashi M., Otsuka H., Takahara A.: Competition between oxidation and coordination in cross-linking of polystyrene copolymer containing catechol groups. American Chemical Society Macro Letters, 1, 457-460 (2012). DOI: $10.1021 / \mathrm{mz} 200217 \mathrm{~d}$

[5] Montarnal D., Cordier P., Soulié-Ziakovic C., Tournilhac F., Leibler L.: Synthesis of self-healing supramolecular rubbers from fatty acid derivatives, diethylene triamine, and urea. Journal of Polymer Science Part A: Polymer Chemistry, 46, 7925-7936 (2008).

DOI: 10.1002/pola.23094

[6] Cordier P., Tournilhac F., Soulié-Ziakovic C., Leibler L.: Self-healing and thermoreversible rubber from supramolecular assembly. Nature, 451, 977-980 (2008). DOI: $10.1038 /$ nature 06669

[7] Burattini S., Colquhoun H. M., Greenland B. W., Hayes W.: A novel self-healing supramolecular polymer system. Faraday Discussions, 143, 251-264 (2009). DOI: 10.1039/B900859D

[8] Kalista S. J., Pflug J. R., Varley R. J.: Effect of ionic content on ballistic self-healing in EMAA copolymers and ionomers. Polymer Chemistry, 4, 4910-4926 (2013).

DOI: $10.1039 / \mathrm{C} 3 \mathrm{PY} 00095 \mathrm{H}$
[9] Krogsgaard M., Behrens M. A., Pedersen J. S., Birkedal H.: Self-healing mussel-inspired multi-pH-responsive hydrogels. Biomacromolecules, 14, 297-301 (2013). DOI: $10.1021 / \mathrm{bm} 301844 \mathrm{u}$

[10] Wei Z., Yang J. H., Zhou J., Xu F., Zrínyi M., Dussault P. H., Osada Y., Chen Y. M.: Self-healing gels based on constitutional dynamic chemistry and their potential applications. Chemical Society Reviews, 43, 81148131 (2014). DOI: 10.1039/C4CS00219A

[11] Yan X., Wang F., Zheng B., Huang F.: Stimuli-responsive supramolecular polymeric materials. Chemical Society Reviews, 41, 6042-6065 (2012).

DOI: $10.1039 / \mathrm{C} 2 \mathrm{CS} 35091 \mathrm{~B}$

[12] Holten-Andersen N., Harrington M. J., Birkedal H., Lee B. P., Messersmith P. B., Lee K. Y. C., Waite J. H.: $\mathrm{pH}$-induced metal-ligand cross-links inspired by mussel yield self-healing polymer networks with nearcovalent elastic moduli. Proceedings of the National Academy of Sciences, 108, 2651-2655 (2011). DOI: $10.1073 /$ pnas. 1015862108

[13] Zhang Y., Tao L., Li S., Wei Y.: Synthesis of multiresponsive and dynamic chitosan-based hydrogels for controlled release of bioactive molecules. Biomacromolecules, 12, 2894-2901 (2011). DOI: $10.1021 / \mathrm{bm} 200423 \mathrm{f}$

[14] Yang B., Zhang Y., Zhang X., Tao L., Li S., Wei Y.: Facilely prepared inexpensive and biocompatible selfhealing hydrogel: A new injectable cell therapy carrier. Polymer Chemistry, 3, 3235-3238 (2012).

DOI: $10.1039 / \mathrm{c} 2 \mathrm{py} 20627 \mathrm{~g}$

[15] Kupfer S., Zedler L., Guthmuller J., Bode S., Hager M. D., Schubert U. S., Popp J., Gräfe S., Dietzek B.: Self-healing mechanism of metallopolymers investigated by QM/MM simulations and Raman spectroscopy. Physical Chemistry Chemical Physics, 16, 12422-12432 (2014). DOI: $10.1039 / \mathrm{c} 4 \mathrm{cp} 00562 \mathrm{~g}$

[16] Zhang Y., Yang B., Zhang X., Xu L., Tao L., Li S., Wei Y.: A magnetic self-healing hydrogel. Chemical Communications, 48, 9305-9307 (2012).

DOI: $10.1039 / \mathrm{c} 2 \mathrm{cc} 34745 \mathrm{~h}$

[17] Schmidt S., Reinecke A., Wojcik F., Pussak D., Hartmann L., Harrington M. J.: Metal-mediated molecular self-healing in histidine-rich mussel peptides. Biomacromolecules, 15, 1644-1652 (2014).

DOI: $10.1021 / \mathrm{bm} 500017 \mathrm{u}$

[18] Deng G., Tang C., Li F., Jiang H., Chen Y.: Covalent cross-linked polymer gels with reversible sol-gel transition and self-healing properties. Macromolecules, 43, 1191-1194 (2011).

DOI: $10.1021 / \mathrm{ma9} 22197$

[19] He L., Fullenkamp D. E., Rivera J. G., Messersmith P. B.: $\mathrm{pH}$ responsive self-healing hydrogels formed by boronate-catechol complexation. Chemical Communications, 47, 7497-7499 (2011). DOI: $10.1039 / \mathrm{C} 1 \mathrm{CC} 11928 \mathrm{~A}$ 
[20] Fullenkamp D. E., Barrett D. G., Miller D. R., Kurutz J. W., Messersmith P.: pH-dependent cross-linking of catechols through oxidation via $\mathrm{Fe}^{3+}$ and potential implications for mussel adhesion. RSC Advances, 4, $25127-$ 25134 (2014). DOI: $10.1039 / C 4 R A 03178 D$

[21] Menyo M. S., Hawker C. J., Waite J. H.: Versatile tuning of supramolecular hydrogels through metal complexation of oxidation-resistant catechol-inspired ligands. Soft Matter, 9, 10314-10323 (2013).

DOI: $10.1039 / \mathrm{C} 3 \mathrm{SM} 51824 \mathrm{H}$

[22] Nakahata M., Takashima Y., Harada A.: Redox-responsive macroscopic gel assembly based on discrete dual interactions. Angewandte Chemie International Edition, 53, 3617-3621 (2014).

DOI: $10.1002 /$ anie.201310295

[23] Zeng H., Hwang D. S., Israelachvili J. N., Waite J. H.: Strong reversible $\mathrm{Fe}^{3+}$-mediated bridging between dopacontaining protein films in water. Proceedings of the National Academy of Sciences, 107, 12850-12853 (2010).

DOI: $10.1073 /$ pnas. 1007416107

[24] Wilker J. J.: The iron-fortified adhesive system of marine mussels. Angewandte Chemie International Edition, 49, 8076-8078 (2010).

DOI: 10.1002/anie.201003171

[25] Taylor S. W., Chase D. B., Emptage M. H., Nelson M. J., Waite J. H.: Ferric ion complexes of a DOPA-containing adhesive protein from Mytilus edulis. Inorganic Chemistry, 35, 7572-7577 (1996).

DOI: $10.1021 /$ ic $960514 \mathrm{~s}$

[26] Yang W., Gao X., Wang B.: Biological and medicinal applications of boronic acids. in 'Boronic acids: Preparation and applications in organic synthesis and medicine' (ed.: Hall D. G.) Wiley, Weinheim, 481-512 (2005).

DOI: $10.1002 / 3527606548 . \operatorname{ch} 13$

[27] Cambre J. N., Sumerlin B. S.: Biomedical applications of boronic acid polymers. Polymer, 52, 4631-4643 (2011).

DOI: $10.1016 /$ j.polymer.2011.07.057

[28] Pizer R., Babcock L.: Mechanism of the complexation of boron acids with catechol and substituted catechols. Inorganic Chemistry, 16, 1677-1681 (1977).

DOI: 10.1021/ic50173a021

[29] Paugam M-F., Valencia L. S., Boggess B., Smith B. D.: Selective dopamine transport using a crown boronic acid. Journal of the American Chemical Society, 116, 11203-11204 (1994). DOI: $10.1021 / \mathrm{ja} 00103 \mathrm{a} 064$

[30] Vatankhah-Varnoosfaderani M., Hashmi S., GhavamiNejad A., Stadler F. J.: Rapid self-healing and triple stimuli responsiveness of a supramolecular polymer gel based on boron-catechol interactions in a novel water-soluble mussel-inspired copolymer. Polymer Chemistry, 5, 512-523 (2014).

DOI: $10.1039 / \mathrm{C} 3 \mathrm{PY} 00788 \mathrm{~J}$
[31] Vatankhah-Varnoosfaderani M., GhavamiNejad A., Hashmi S., Stadler F. J.: Mussel-inspired pH-triggered reversible foamed multi-responsive gel - The surprising effect of water. Chemical Communications, 49, 46854687 (2013). DOI: $10.1039 / \mathrm{C} 3 \mathrm{CC} 41332 \mathrm{~B}$

[32] Kan Y., Danner E. W., Israelachvili J. N., Chen Y., Waite J. H.: Boronate complex formation with Dopa containing mussel adhesive protein retards $\mathrm{pH}$-induced oxidation and enables adhesion to mica. PLOS One, 9, e108869/1- e108869/7 (2014). DOI: $10.1371 /$ journal.pone.0108869

[33] Nishiyabu R., Kubo Y., James T. D., Fossey J. S.: Boronic acid building blocks: Tools for self assembly. Chemical Communications, 47, 1124-1150 (2011). DOI: 10.1039/C0CC02921A

[34] Nakahata M., Mori S., Takashima Y., Hashidzume A., Yamaguchi H., Harada A.: pH- and sugar-responsive gel assemblies based on boronate-catechol interactions. American Chemical Society Macro Letters, 3, 337340 (2014). DOI: $10.1021 / \mathrm{mz} 500035 \mathrm{w}$

[35] White E. M., Seppala J. E., Rushworth P. M., Ritchie B. W., Sharma S., Locklin J.: Switching the adhesive state of catecholic hydrogels using phototitration. Macromolecules, 46, 8882-8887 (2013).

DOI: $10.1021 / \mathrm{ma} 401594 \mathrm{z}$

[36] Lin W., Kim D.: pH-sensitive micelles with crosslinked cores formed from polyaspartamide derivatives for drug delivery. Langmuir, 27, 12090-12097 (2011). DOI: $10.1021 / 1 \mathrm{a} 200120 \mathrm{p}$

[37] Scialabba C., Rocco F., Licciardi M., Pitarresi G., Ceruti M., Giammona G.: Amphiphilic polyaspartamide copolymer-based micelles for rivastigmine delivery to neuronal cells. Drug Delivery, 19, 307-316 (2012). DOI: $10.3109 / 10717544.2012 .714813$

[38] Ma Y., Jiang X., Zhuo R.: Biodegradable and thermosensitive polyaspartamide derivatives bearing aromatic structures. Materials Letters, 121, 78-80 (2014). DOI: $10.1016 /$ j.matlet.2014.01.150

[39] Heo S-B., Jeon Y-S., Kim Y-J., Kim S-H., Kim J-H.: Bioinspired self-adhesive polymer for surface modification to improve antifouling property. Journal of Coatings Technology and Research, 10, 811-819 (2013). DOI: $10.1007 / \mathrm{s} 11998-013-9528-9$

[40] Neri P., Antoni G., Benvenuti F., Colola F., Gazzei G.: Synthesis of $\alpha, \beta$-poly [(2-hydroxyethyl)-DL-aspartamide], a newplasma expander. Journal of Medicinal Chemistry, 16, 893-897 (1973). DOI: $10.1021 / \mathrm{jm} 00266 \mathrm{a} 006$

[41] Ishihara K., Mouri Y., Funahashi S., Tanaka M.: Mechanistic study of the complex formation of boric acid. Inorganic Chemistry, 30, 2356-2360 (1991). DOI: $10.1021 / \mathrm{ic} 00010 \mathrm{a} 025$ 